\title{
Review Article \\ Diagnosis of Infections Caused by Pathogenic Free-Living Amoebae
}

\author{
Bruno da Rocha-Azevedo, ${ }^{1}$ Herbert B. Tanowitz, ${ }^{2}$ and Francine Marciano-Cabral ${ }^{1}$ \\ ${ }^{1}$ Department of Microbiology and Immunology, Virginia Commonwealth University School of Medicine, Richmond, VA 23298, USA \\ ${ }^{2}$ Department of Pathology, Albert Einstein College of Medicine, Bronx, NY 10461, USA
}

Correspondence should be addressed to Francine Marciano-Cabral,fmcabral@vcu.edu

Received 25 March 2009; Accepted 5 June 2009

Recommended by Louis M. Weiss

\begin{abstract}
Naegleria fowleri, Acanthamoeba spp., Balamuthia mandrillaris, and Sappinia sp. are pathogenic free-living amoebae. N. fowleri causes Primary Amoebic Meningoencephalitis, a rapidly fatal disease of the central nervous system, while Acanthamoeba spp. and B. mandrillaris cause chronic granulomatous encephalitis. Acanthamoeba spp. also can cause cutaneous lesions and Amoebic Keratitis, a sight-threatening infection of the cornea that is associated with contact lens use or corneal trauma. Sappinia pedata has been identified as the cause of a nonlethal case of amoebic encephalitis. In view of the potential health consequences due to infection with these amoebae, rapid diagnosis is critical for early treatment. Microscopic examination and culture of biopsy specimens, cerebral spinal fluid (CSF), and corneal scrapings have been used in the clinical laboratory. For amoebic keratitis, confocal microscopy has been used to successfully identify amoebae in corneal tissue. More recently, conventional and real-time PCR assays have been developed that are sensitive and specific for the amoebae. In addition, multiplex PCR assays are available for the rapid identification of these pathogens in biopsy tissue, CSF, and corneal specimens.
\end{abstract}

Copyright (C) 2009 Bruno da Rocha-Azevedo et al. This is an open access article distributed under the Creative Commons Attribution License, which permits unrestricted use, distribution, and reproduction in any medium, provided the original work is properly cited.

\section{Introduction}

Free-living amoebae (FLA) are found in soil and water habitats throughout the world. These amoebae ingest bacteria, yeast, and other organisms as a food source. Unlike "true" parasites, pathogenic FLA can complete their life cycles in the environment without entering a human or animal host. Of the many FLA that are found in the environment, four genera of FLA have been associated with human disease. One species of Naegleria, $N$. fowleri, one species of Balamuthia, $B$. mandrillaris, and several species of Acanthamoeba can cause fatal central nervous system (CNS) infections. In addition to a CNS infection, Acanthamoeba can cause cutaneous lesions and Amoebic Keratitis, a sight-threatening infection of the cornea [1-8]. Human infections with these amoebae have been reported from all over the world $[3,5]$. More recently, a newly recognized pathogen was detected in brain tissue of a patient with CNS symptoms who survived the infection. Although the amoebae was not isolated from the patient, it was identified by light and electron microscopy as a species of Sappinia. Sappinia sp. has not been shown to be lethal in humans or experimental animals $[9,10]$. Figure 1 shows the morphology of trophozoites of N. fowleri (A), Acanthamoeba spp. (B), and B. mandrillaris (C), by scanning electron microscopy.

Pathogenic FLA can be isolated from freshwater lakes, thermally polluted waters, sediment, thermal springs, swimming pools, soil, air conditioning vents, air, and the domestic water supply $[3,6,11-14]$. In addition to causing human disease, FLA also can harbor intracellular pathogenic bacteria such as Legionella pneumophila and may serve as vectors of bacterial infections in humans $[15,16]$. A number of clinical FLA isolates from corneal and cutaneous lesions have been shown to harbor bacterial endosymbionts or pathogens [16-20]. Laboratory studies, also, have shown that a number of pathogenic bacteria including Mycobacterium avium, Burkholderia spp., Escherichia coli O157:H7, and Vibrio cholerae, can survive and multiply in FLA $[6,21-$ 26]. Intracellular growth of bacteria within amebae has been shown to increase bacterial resistance to antibiotics and to biocides, and to increase bacterial virulence [20, 23-26]. 
Since the majority of FLA infections are fatal and diagnosed postmortem, it is important to recognize the diseases and to develop more rapid diagnostic methods. The mode and pathogenesis of infection differ for each of the FLA that cause human infections.

\section{Naegleria fowleri and Primary Amoebic Meningoencephalitis (PAM)}

The amoeboflagellate, N. fowleri, has three morphological forms in its life cycle, an amoeba or trophozoite stage (Figure 1(a)) that feeds and divides, a swimming flagellate that seeks out a new food source, and a resistant cyst that protects the amoebae from adverse environmental conditions. N. fowleri causes Primary Amoebic Meningoencephalitis (PAM), an acute, fulminant, rapidly fatal disease that occurs generally in previously healthy children and young adults with a history of swimming and diving and other recreational activities in fresh water and contaminated swimming pools [1-3, 27-29]. Two other species of Naegleria, N. australiensis and $N$. italica can cause infections in mice but have never been identified from human infections [5]. Cases of PAM caused by $N$. fowleri have occurred also from contaminated domestic water used for bathing $[11,12]$. Infection can occur when amebae enter the nasal passages, attach to the olfactory mucosa, and migrate through the cribriform plate alongside the olfactory nerves. Once in the olfactory bulbs of the brain, the amebae divide rapidly and death occurs within 7 to 10 days. N. fowleri causes a fulminating hemorrhagic necrosis of the brain. An inflammatory infiltrate consisting of neutrophils, eosinophils, and macrophages is histopathological characteristic of infected brain tissue. Only trophozoites are found in the brain $[3-5,29]$. Survival from PAM is dependent on rapid diagnosis and treatment of the disease and has occurred when the disease was recognized early and treatment initiated promptly [30,31]. Survival rate is improved when a combination of amphotericin B is used intravenously, with intrathecal administration of amphotericin $B$ and oral rifampin and other antifungal agents [30-34]. Amphotericin $\mathrm{B}$ and fluconazole administered intravenously followed by oral rifampicin resulted in successful treatment of a child who developed PAM [35]. However, not all patients treated with Amphotericin B survive [36-38]. Others have suggested that a triple combination of low dose amphotericin B administered intravenously (IV) with oral rifampacin and oral ketoconazole would result in a more favorable outcome [39]. Azithromycin has been shown to be effective against $N$. fowleri in vitro (cell culture) and in vivo (mouse model of infection) [8]. However, optimal treatment remains to be developed.

2.1. Symptoms of PAM Infection. PAM is characterized by the sudden onset of severe frontal headache, fever, nausea, vomiting, and rhinitis. These are followed by stiff neck, diplopia, loss of the sense of smell, confusion, and occasional seizures, progressing rapidly to coma and death. An elevated white cell count is usual with a marked increase in neutrophils. CSF contains neutrophils, and thus a bacterial infection is often suspected $[3-5,7]$. A history that describes contact with warm water (diving, wakeboarding, water skiing) is suggestive of PAM [40].

2.2. Laboratory Diagnosis. PAM is a rare disease but almost always fatal. Therefore, early diagnosis is important in order to start treatment. The disease is often misdiagnosed because no distinctive differences in diagnosis exist to distinguish PAM from bacterial meningoencephalitis.

2.2.1. Imaging Methods. Computed Tomography (CT) scans or Magnetic Resonance Imaging (MRI) shows lesions but these are nonspecific [41-43]. CT scans show obliteration of the cisterns surrounding the midbrain and the subarachnoid space [3].

2.2.2. Microscopic Methods. Premortem diagnosis is rare, but when CSF pressure is low, lumbar puncture can be performed. CSF is purulent, and when bacteria are not found, amoebic meningoencephalitis should be considered. The CSF is cloudy and slightly hemorrhagic with increased cellularity composed mainly of neutrophils. CSF is characterized by low glucose and elevated protein. Direct microscopic examination of CSF as a wet mount is the method of choice in the diagnosis of PAM because CSF contains motile amoebae which can be recognized by light microscopic observation $[5,44,45]$. N. fowleri can be distinguished from other FLA that cause CNS infections because amoebae can transform into swimming flagellates when amoebae are placed in water. If present in CSF, amoebae can be identified by staining fixed preparations with Wright's, Giemsa, or hematoxylin and eosin (H \& E). Although Gram stain is used in clinical laboratories for detection of bacteria in CSF, Gram stain is not useful for diagnosis of amoebae because it does not depict the characteristic nuclear morphology of the amoebae. Amoebae can be mistaken as macrophages, but $N$. fowleri nucleus contains a large, central, round nucleolus which should distinguish it from host cells $[3,27,44,45]$.

Polyclonal antibodies produced in rabbits or monoclonal antibodies can be used to identify amoebae in tissue sections and CSF. Amoebae in CSF can be identified by specific indirect immunofluorescent antibody assays using a polyclonal or monoclonal antibody to the amoeba in conjunction with a flouresceinated secondary antibody $[3,45,46]$.

Biopsy material should be fixed in 10\% neutral buffered formalin for histological examination. Amoebae can be observed in biopsied brain tissue following $\mathrm{H} \& \mathrm{E}$ staining or by immunoperoxidase staining using antibodies to the amoebae. Only trophozoites are found in brain tissue; cysts are not observed [3].

A commercially available enzyme-linked immunosorbent assay (Indicia, Oulin, France) based on the use of a monoclonal antibody (5D12) that recognizes a glycosylated epitope on N. fowleri can be used to diagnose infections. This monoclonal antibody can be used to distinguish N. fowleri from other species of Naegleria, and from other FLA in tissue and in environmental samples [46, 47]. 


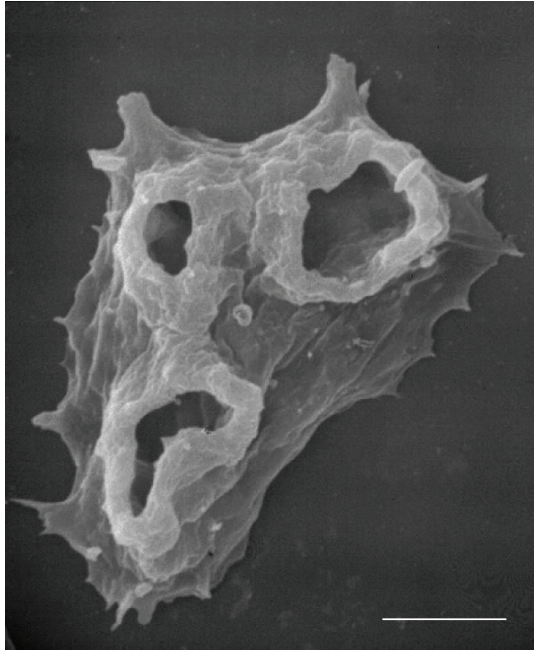

(a)

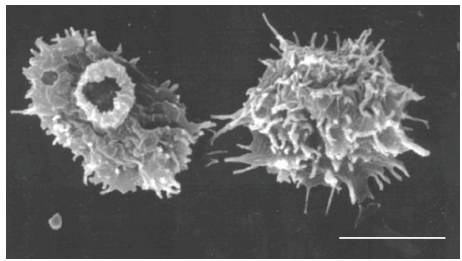

(b)

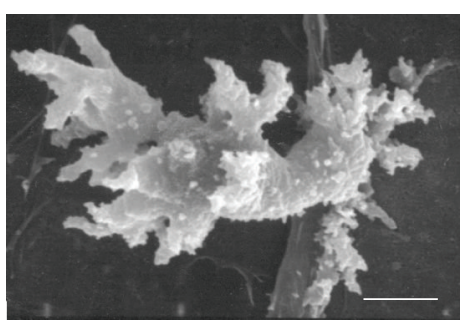

(c)

Figure 1: Fine morphology of trophozoites of N. fowleri, (a) Acanthamoeba spp., (b) and B. mandrillaris, (c) by Scanning Electron Microscopy. Bars represent $5 \mu \mathrm{m}$.

2.2.3. Culture Methods. CSF or biopsied brain tissue should be kept and transported at room temperature to the diagnostic laboratory. This material can be inoculated onto tissue culture cells (Vero, fibroblasts) and incubated at $37^{\circ} \mathrm{C}$ in the presence of the antibiotics, penicillin-streptomycin. Fungicides are lethal to the amoebae. Amoebae that are present will multiply and destroy the monolayer in 24 to 48 hours. Biopsy tissue also can be placed on 1.5\% nonnutrient agar coated with a layer of bacteria (Escherichia coli). The amoebae will emerge from the tissue, ingest the bacteria, and divide. The amoebae, then, can be observed on the agar using an inverted light microscope $[3,44,45,48]$.

2.2.4. Serology. Antibodies to Naegleria spp. have been identified in healthy individuals $[49,50]$. Since PAM is a rapid disease, serological tests for an increase in antibody titer are not always helpful. Generally, there is not a rise in antibody titer although a rise in antibody has been observed in a patient that was successfully treated and survived the infection [30].

2.2.5. Polymerase Chain Reaction (PCR) Assays. More rapid molecular techniques are now available in research laboratories, but these methods generally are not available in most clinical laboratories. Highly specific and sensitive PCR and real-time PCR assays have been developed for the detection of N. fowleri in clinical and environmental samples [5157]. A PCR assay using primers for the complete ribosomal internal transcribed spacer region (ITS) has been developed that allows for the discrimination of Naegleria species, and a species specific assay allows for detection of $N$. fowleri $[51,52]$. A PCR assay that detects $N$. fowleri in fresh brain tissue as well as in formalin-fixed paraffin-embedded brain tissue also has been reported [56]. Recently, Qvarnstrom et al., [57] developed a fast and sensitive multiplex real-time PCR assay based on the use of probes targeting the partial or full length nuclear small subunit ribosomal genes (18S rRNA gene) for simultaneous detection of Naegleria, Balamuthia, and Acanthamoeba [57]. This PCR assay is species specific for N. fowleri and B. mandrillaris and genus specific for Acanthamoeba. Thus, this assay can identify which amoebae is present in a CSF sample or a brain biopsy specimen from an amoebic encephalitis patient. The detection limit for this assay was shown to be one amoebae per sample.

\section{Acanthamoeba spp.}

Acanthamoeba is one of the most commonly isolated amoebae in environmental samples. Acanthamoeba is ubiquitous and found in a variety of habitats including domestic water supplies, hospital water, dental water units, air, soil, and water. Acanthamoeba has two morphological forms in its life cycle, a trophozoite (Figure 1(b)) and a cyst stage. Both stages can be found in tissues of infected humans and in the environment. The trophozoite is the dividing form and is thought to be the infective stage. The cysts are dormant and protect the amoebae from harmful environments. The cysts are resistant to biocides, chlorination, and antibiotics. Several species of Acanthamoeba can cause Granulomatous Amoebic Encephalitis (GAE), cutaneous acanthamoebiasis, or Amoebic Keratitis (AK). AK is a sight-threatening infection of the cornea that occurs in immune competent individuals, mainly contact lens users. GAE, also known as Acanthamoeba Granulomatous Encephalitis (AGE), is a rare, chronic, progressive infection of the CNS that may involve the lungs [58]. GAE is usually associated with an underlying debilitating disease or immune suppressed individuals including HIV-AIDS patients, diabetics, individuals undergoing organ transplants or cancer chemotherapy, and drug abusers $[6,7,58,59]$. Cutaneous lesions caused by Acanthamoeba also have been described. Cutaneous acanthamoebiasis has been reported more frequently in HIV 
positive patients than in other conditions [60-66]. The manifestations of cutaneous infection include the presence of numerous hard erythematous nodules, papules, or ulcers along the patient's body [62-67]. The presence of both skin lesions and CNS symptoms occurring simultaneously can be suggestive of an Acanthamoeba infection [58].

3.1. Symptoms of GAE. GAE symptoms include headaches, slight fever, seizures, hemiparesis, cranial nerve palsies, personality changes, nausea, stiff neck, depressed level of consciousness and coma, typical clinical signs of a localized encephalopathy [5-8]. The clinical signs of GAE are not specific. Thus, the disease is often misdiagnosed as bacterial leptomeningitis, tuberculous meningitis, viral encephalitis, toxoplasmosis, fungal infections, neurocysticercosis, or a brain tumor $[5,6,68-71]$.

\subsection{Diagnostic Methods}

3.2.1. Imaging Methods. Brain imaging methods, such as CT and MRI, have been used to visualize brain lesions caused by Acanthamoeba, but the lesions themselves are not specific for GAE [41-43]. Multifocal low-density lesions in both cortical and subcortical regions of the brain can be observed using CT scans. Enhanced CT normally shows the presence of progressive hydrocephalus, with meningeal thickening, pseudotumoral lesions, large isolated lesions, or multiple oval lesions. Multifocal lesions, edema, and multiple ringenhancing lesions are commonly observed in GAE patients by MRI. Despite these characteristics, both CT and MRI have limited diagnostic value for GAE [5, 7, 41-43, 68-73].

3.2.2. Microscopic Methods. The definitive diagnosis of GAE is the detection of the amoeba in tissue or isolation of the amoeba. To achieve visual detection of both Acanthamoeba trophozoites and cysts in brain tissue, skin lesions, or cerebrospinal fluid (CSF), both light and electron microscopy can be used. Acanthamoeba trophozoites can be distinguished from host inflammatory cells such as macrophages mainly by their nuclear structure, since Acanthamoeba possesses a rounded nucleus and a large central nucleolus, forming a halo $[3,6,59]$. However, it is not possible to differentiate Acanthamoeba trophozoites from pathogenic $B$. mandrillaris trophozoites by light microscopy, since both amoebae possess the same nuclear structure [7]. Biopsy or autopsy specimens should be formalin-fixed, paraffinembedded, and stained with $\mathrm{H} \& \mathrm{E}$ [74]. Other types of histological staining have been used, including Periodic Acid Shiff, Gomori's methenamine silver, or trichome. These stains appear to be effective in identifying cysts [75, 76]. Acridine orange and calcofluor white have been used successfully to observe Acanthamoeba cysts in tissues $[6,77,78]$.

Brain granulomas, necrosis with the presence of multinucleated cells, inflammatory infiltrates, and amebas (both trophozoites and cysts) surrounding blood vessels [3-5] can be observed in biopsied tissue stained with $\mathrm{H}$ \& E. Amoebae, also, can be detected in CSF in wet preparations or Giemsa stained slides of CSF sediments $[29,79,80]$. For the diagnosis of cutaneous acanthamoebiasis, light microscopic examination of $\mathrm{H} \& \mathrm{E}$ stained skin biopsies demonstrates the presence of granulomas, areas of necrosis, inflammatory infiltrates, and vasculitis containing both trophozoites and cysts of Acanthamoeba [62, 64, 67, 75, 81].

The use of both fluorescence microscopy and immunohistochemistry in brain and skin tissue sections is efficient methods to specifically detect Acanthamoeba [82-87]. AntiAcanthamoeba antibodies generated in rabbits can be used to identify amoebae in tissue. Patient specimens are incubated with anti-Acanthamoeba antibodies followed by a secondary antirabbit IgG associated with a fluorescent marker to detect both trophozoites and cysts [74]. More recently, speciesspecific monoclonal antibodies were developed to use as an important diagnostic and epidemiological tool. These monoclonal antibodies recognize A. castellanii, A. polyphaga, A. lenticulata, and A. culbertsoni, react with formalin-fixed, paraffin-embedded infected tissues, and recognize both the trophozoite and cyst stages of the amoebae [88].

Transmission electron microscopy (TEM) also can be used as a tool to differentiate cysts and trophozoites of Acanthamoeba from host cells and from other amoebae, such as $B$. mandrillaris $[63,70,89,90]$. However, this technique is expensive; sample preparation is time consuming and requires personnel with expertise.

3.2.3. Culture Methods. Isolation and culture of Acanthamoeba can be performed by placing brain or skin biopsy/autopsy samples on $1.5 \%$ nonnutrient agar plates covered with a layer of Escherichia coli or Enterobacter aerogenes $[3,7,48,58,83,91]$. Depending on the density of amoebae, Acanthamoeba can be observed after 24 hours of inoculation. Samples, also, can be placed on tissue culture cells in the presence of antibiotics (penicillin-streptomycin and gentamicin) in which case the amoebae destroy the cell monolayer in 24 to 48 hours depending on the number of amoebae present $[3,6,59]$.

3.2.4. Serology. To detect Acanthamoeba infections, an increase in antibody titer can be an indication of infection. For this evaluation, indirect immunofluorescence (IIF) is performed using serial dilutions of serum from an individual suspected of having Acanthamoebiasis, followed by incubation of the sera with slides containing fixed amoebae or amoebic extracts. The detection can be achieved by adding an anti-IgG antibody associated with a fluorescent label such as FITC, and antibody detection and titration can be determined by fluorescence microscopy [92]. Acanthamoeba infected individuals possess high antibody titers (between $1: 256$ and $1: 1024)$ in serum while healthy individuals who have been exposed to Acanthamoeba in the environment have low antibody titers, usually not higher than $1: 80$ [82, 92-96]. Thus, IIF can be a useful tool to confirm infection in patients who are suspected of being infected with Acanthamoeba [96]. Western immunoblot analysis, also, has been used to demonstrate antibodies to Acanthamoeba in human serum [97]. An ELISA method utilizing whole fixed trophozoites rather than disrupted amoebic extracts 
as the antigen source was developed and shown to be an effective tool for identifying antibodies to Acanthamoeba in the clinical laboratory setting [98].

3.2.5. PCR. Detection of Acanthamoeba can be rapidly achieved by using molecular methods. For diagnostic purposes, the detection of Acanthamoeba at the genus level is sufficient to recognize whether an individual is infected. Molecular identification of Acanthamoeba can be performed by polymerase chain reaction assays [99101]. The complete DNA gene sequence of the $18 \mathrm{~S}$ ribosomal RNA gene (18S rDNA) permitted the design of a reliable primer pair specific for Acanthamoeba genus, called JDP1 and JDP2. Use of the JDP1 (forward primer) 5'-GGCCCAGATCGTTTACCGTGAA and the JDP2 (reverse primer) 5'-TCTCACAAGCTGCTAGGGAGTCA, respectively, results in a specific amplimer of $500 \mathrm{bp}$, called ASA.S1. An advantage of this PCR assay is that it detects all known Acanthamoeba subgroups [100]. This PCR assay has been successfully used to detect Acanthamoeba in the environment as well as in patients with GAE and cutaneous acanthamoebiasis [83, 102-105]. However, DNA amplification from cysts is a troublesome task. Thus, treatment of cysts with proteinase $\mathrm{K}$ prior to DNA extraction has been suggested to increase the positive results by PCR assays [106].

Studies have shown that the majority of GAE and AKcausing amoebae have a specific PCR product (these amoebae are included in a subgroup called T4), when primers to amplify the small subunit rRNA genes (SSU rDNA) are used [107]. Mitochondrial DNA PCR, also, has been used successfully to detect Acanthamoeba from brain slices and CSF [108, 109]. Real-time PCR has been used as a fast tool to differentially identify free-living amoebae and to differentiate Acanthamoeba from N. fowleri and B.mandrillaris $[57,110]$. A real time PCR assay developed by Rivière et al.,[110] utilizes Taqman technology to detect $18 \mathrm{~S}$ ribosomal DNA (rDNA). This assay, based on the Acanthamoeba T4 genotype, does not detect other genotypes such as T10. The real time PCR assay developed by Qvarnstrom et al., [57] is a triplex assay to distinguish Acanthamoeba from other pathogenic FLA and is more complete in that it was designed to detect a broader range of Acanthamoeba genotypes. Both real time assays have been validated by testing a number of positive and negative clinical samples [111].

\section{Acanthamoeba spp. and Amoebic Keratitis (AK)}

In contrast to GAE, which is a chronic infection, $\mathrm{AK}$ is an acute, painful infection that can occur in immune competent individuals. This disease is related to the use of contact lenses or previous corneal trauma. When $\mathrm{AK}$ is not treated promptly, loss of visual acuity and blindness can occur $[6,7,58,59,112-116]$.

4.1. Symptoms of $A K$. Initial symptoms of $\mathrm{AK}$ are not specific and include disproportional eye pain, photophobia, eye redness, and tearing, usually affecting one eye [116]. However, bilateral AK has been described, as a complication of the initial infection [116]. Using a slit-lamp, corneal inflammation leading to formation of a ring-like stromal infiltrate can be observed. Furthermore, corneal epithelial erosion, irregularities, and edema are present. The radial perineural distribution of the infiltrate (radial keratoneuritis) is characteristic for $\mathrm{AK}$, similar to the type of infiltration observed in Pseudomonas aeruginosa keratitis [112-115, 117-120]. Later stages of infection can result in epithelial denudation and stromal necrosis. Contact lens usage and/or incidents of corneal trauma are strong indicators for AK [121-123]. Despite the clinical picture, AK is often misdiagnosed as herpes or bacterial keratitides which exhibit similar clinical symptomatology $[114,124,125]$.

\subsection{Diagnostic Methods}

Diagnosis of AK can be undertaken by analysis of the clinical appearance of the cornea and by the demonstration of amoebae in the cornea $[112,125]$.

4.2.1. Microscopic Methods. The detection of Acanthamoeba can be achieved by analysis of a corneal biopsy. However, corneal scraping has been an efficient and noninvasive method used to isolate amoebae and to diagnose Acanthamoeba keratitis [126]. After scraping, samples can be smeared on glass slides. Light microscopy is an efficient means to detect Acanthamoeba in corneal scrapings, in biopsy samples, and in keratoplasty specimens. Acanthamoeba can be detected in wet-mount preparations of corneal scraping, using 10\% KOH [126-132]. Moreover, impression cytology was able to remove amoebic specimens of an AK patient [132]. H \& E and Giemsa stains have been used successfully to detect both trophozoites and cysts of Acanthamoeba. Cysts stained by Giemsa or $\mathrm{H}$ \& E are clear, bright with polyhedric or stellate shaped cysts, while trophozoites, with the central nucleolus and vacuoles, are more difficult to detect, since they can resemble inflammatory cells $[112,115,129,130,133-135]$. PAS stain also has been used for detection of cysts [128, 136]. As described previously, IIF assays and immunofluorescence microscopy can be used to detect Acanthamoeba in brain and skin tissue, as well as in corneal specimens, contact lenses, and lens cases $[134,137,138]$. Immunoperoxidase technique is also efficient to detect Acanthamoeba in host tissue $[121,134]$. Cysts and trophozoites are easily detected by transmission electron microscopy [133].

Fluorescent stains have been used to detect Acanthamoeba cysts in corneal samples. Calcofluor white is a fluorescent compound that is able to bind cellulose in the cell wall of Acanthamoeba cysts found in corneal scrapings and paraffin-embedded sections of corneal tissue [138, 139]. Furthermore, specimens previously stained with $\mathrm{H} \& \mathrm{E}$, and other stains can be stained subsequently with calcofluor white, which is rapid and efficient but requires a fluorescence microscope. It is also important to note that in mixed fungi, Acanthamoeba infections, both pathogens will be stained, 
since both amoebic cysts and fungi cell walls are possible targets for calcofluor white. Acridine orange, another fluorochromatic dye, has been used for rapid diagnosis of AK [78]. The use of fluorescent dyes may lead to falsepositive staining patterns of cell debris $[129,130]$; therefore, an experienced observer and a fluorescence microscope are necessary for a proper diagnosis.

The use of in vivo confocal microscopy to detect Acanthamoeba in corneal tissue at distinct depths, in real time, without any invasive procedure has been successfully used to diagnose AK [140-148]. In a recent Chicagoarea outbreak, in conjunction with other methods, such as culturing or light microscopy, confocal microscopy was used to detect Acanthamoeba [148]. High-contrast rounded bodies, indicative of amoebic cysts, are commonly observed $[143,146,147]$. Limitations of confocal microscopy as a definitive diagnostic tool for AK have been presented [149]. However, studies have shown that when confocal microscopy was used by experienced operators, the technique is sensitive and specific for detection of Acanthamoeba in corneal tissue [148].

4.2.2. Culture Methods. As described previously for GAE, culture of amoebae from corneal biopsies or scrapings and washes from contact lenses or lens cases is still the most common, cheap, and efficient method to detect Acanthamoeba. Samples from the infected cornea are inoculated on $1.5 \%$ nonnutrient agar plates covered with E. coli or other nonmucoid bacteria. The plates can be incubated at 28 $30^{\circ} \mathrm{C}$ for days to weeks, which depends on the number of amoebae in the samples. The presence of amoebae can be checked by using an inverted microscope $[48,150]$.

4.3. PCR. As described previously for GAE and cutaneous lesions, PCR probes have been used, also, to confirm the presence of amoebae in corneal biopsies and scrapings, contact lenses, lens cases, lens solutions, and also in the environment $[57,100,110,151,152]$. Moreover, PCR is an efficient method to detect Acanthamoeba in tear samples [153], a completely noninvasive way to perform AK diagnostics. The sensitivity of PCR methods to diagnose AK was compared with direct microscopic examination and culture, and it was reported that PCR was more sensitive than morphological detection [154]. Two real time PCR assays have been validated to use as diagnostic tests for AK [57, 110]. However, it has been shown that a number of commonly used topical ophthalmic drugs have an inhibitory effect on PCR assays [155]. Thus, it is important that ophthalmologists rinse the eye surface extensively to remove any inhibitory substances to minimize the risk of misdiagnosis due to false negative PCR results.

\section{Balamuthia mandrillaris and Balamuthia Amoebic Encephalitis (BAE)}

B. mandrillaris is the only species of Balamuthia known to cause infection in humans or animals. Balamuthia was first isolated from the brain of a mandrill baboon that died at the San Diego Zoo from meningoencephalitis. The amoebae was first described as a leptomyxid amoebae but later identified and named Balamuthia mandrillairs [156159]. The life cycle of Balamuthia consists of a trophozoite (Figure 1(c)) and a cyst state. The amoeba is found in soil, but its presence in water has been suggested based on cases of BAE occurring in animals and humans that had a history of swimming in stagnant water [160-163]. Although Balamuthia is considered an opportunistic pathogen, it can cause disease in both immune compromised and immune competent individuals. Infections can occur in children and adults. The incubation period of BAE is extended, and therefore the source and mode of infection have not been definitively determined. It has been suggested that the portal of entry may be via cutaneous lesions, nasal passages, or inhalation via the respiratory tract with subsequent hematogenous spread to the brain and other organs [159].

5.1. Symptoms of BAE. The encephalitis caused by B. mandrillaris, also, is a rare disease with nonspecific symptoms. Symptoms of BAE are chronic and include headaches, nausea, vomiting, fever, myalgia, seizures, weight loss, hemiparesis, and speech difficulties, usually associated with previous skin granulomatous lesions. The aforementioned symptoms are confusing, since they are similar to other brain infections, including tuberculosis, toxoplasmosis, cysticercosis, meningitis, and also brain tumors [7, 158, 164-169].

\subsection{Diagnostic Methods}

5.2.1. Imaging Methods. Brain lesions caused by B. mandrillaris can be detected by neuroimaging, such as CT scans and MRI [170-172]. Focal enhancing lesions, cystic lesions, edema, and hydrocephalus can be observed $[172,173]$. The lesions can mimic other types of disease, such as gliomas, brain abscesses, and hematomas [7]. Thus, the lack of specificity makes the proper diagnosis by imaging methods difficult.

5.2.2. Microscopic Methods. Light microscopy can be used to detect the presence of $B$. mandrillaris in host tissue. Balamuthia has often been identified as Acanthamoeba in tissue because both amoebae cause granulomatous amoebic encephalitis. Amoebae can be observed from brain and skin biopsies and autopsies [174-176]. Unlike infection with N. fowleri, B. mandrillaris is generally not seen in CSF preparations, although it has been isolated from CSF of a 33year-old patient that died of BAE [7, 177]. In the majority of cases described, B. mandrillaris was observed in brain biopsy specimens embedded in paraffin and processed for H\&E $[158,170,175,178]$. Areas of inflammation, granulomas, and the presence of trophozoites and cysts of B. mandrillaris, especially around blood vessels, are observed $[165,169,179]$. Trophozoites show an oval-to-round shape, with a single nucleus and a large nucleolus, while cysts are rounded with a thick wall. However, these morphological characteristics 
are not adequate to differentiate $B$. mandrillaris from Acanthamoeba spp., and also the ability to differentiate these amoebae from host macrophages requires expertise [7, 84].

Antibodies are crucial to the specific detection of $B$. mandrillaris in tissues. Studies have confirmed, both in biopsies and autopsies, the presence of $B$. mandrillaris in brain and skin tissue $[84,157,170,174,178]$. Usually, paraffin-embedded specimens are sectioned and incubated with rabbit anti-Balamuthia serum, and a FITC-conjugated secondary antibody against rabbit IgG is used to detect amoebae with high degree of specificity [159].

It is possible to identify B. mandrillaris in biopsies with the use of transmission electron microscopy (TEM). Unlike host cells, trophozoites contain a characteristic dense nucleolus, and the cytoplasm contains many vesicles. Furthermore, TEM can distinguish B. mandrillaris from Acanthamoeba, since B. mandrillaris possesses a tripledwalled cyst, a distinctive trait when compared to the doubledwalled cyst of Acanthamoeba [158, 159].

5.2.3. Culture Methods. Isolation of B. mandrillaris from biopsy specimens is possible; however amoebic growth is slow and also requires the use of tissue culture cells as a food source, since B. mandrillaris does not feed on bacteria $[48,157-159]$. This is not a recommended method.

5.2.4. Serology. One of the characteristics of B. mandrillaris infection is the high concentration of antibodies to the amoebae in host serum [180-182]. It is possible to determine an infection in humans suspected of having BAE by the presence of antibodies against $B$. mandrillaris in their sera using enzyme-linked immunoassays (ELISAs). This methodology was used to screen a group of encephalitis patients in California, and it was shown that 7 individual samples from 290 were positive for B. mandrillaris [181]. Antibodies to $B$. mandrillaris do not cross-react with other amoebae [180]. Thus, ELISA technique can be useful for screening of samples containing large number of individuals. More recently, flow cytometry was successfully used to detect and quantify antibodies against $B$. mandrillaris in both healthy and diseased individuals [182].

5.2.5. PCR. Rapid and highly specific B. mandrillaris detection can be achieved by using polymerase chain reaction methodology. B. mandrillaris is a well-defined phylogenetic species, with no SSU rDNA sequence variation between isolates and low levels of mitochondrial DNA variation. Booton and coworkers $[183,184]$ developed specific primers from a portion of the mitochondrial rRNA gene (rns). The PCR reaction of these primers resulted in a 1075 bp product, where the product is specific for B. mandrillaris and not for Acanthamoeba. Detection of B. mandrillaris was performed successfully on clinical samples using these primers, both in brain tissue, and CSF $[177,185,186]$. The sensitivity of the PCR detection was tested, and it was observed that 0.2 amoebae were enough for amplification, since mitochondrial DNA had been used [186], indicating that the employment of PCR was an efficient diagnostic tool. The efficacy of
PCR method was compared with IIF as a diagnostic tool on archival brain tissue and a high degree of agreement was reported [109]. By using distinct primers, a multiplex real time PCR to detect B. mandrillaris was developed, with rapid test completion time and high sensitivity, detecting one amoebae per sample [57]. This multiplex assay has been validated and is recommended for detection of FLA in clinical samples [111]. More recently, a real time PCR assay was developed for B. mandrillaris, targeting the RNAase P gene [187]. Sensitivity and specificity were observed, with the probes able to detect small amounts of amoebic DNA.

\section{Sappinia pedata and Sappinia Amoebic Encephalitis (SAE)}

The free-living amoeba, Sappinia, a newly discovered human pathogen of the central nervous system (CNS), can cause amoebic encephalitis in humans $[9,10]$. There are two species of Sappinia, S. pedata and S. diploidea. Sappinia has a worldwide distribution and has been isolated from elk and buffalo feces, soil contaminated with bovine feces, decaying ground plant litter and fresh water $[188,189]$. The life cycle of Sappinia consists of two stages, a trophozoite and a cyst [190]. The first and only case of amoebic encephalitis caused by Sappinia sp. occurred in a previously healthy immune competent adult male who survived the infection. The incubation period and the route of infection are unknown but thought to be by inhalation through the nasopharynx or by hematogenous spread to the brain [9]. The amoeba that caused this encephalitis was originally identified as $S$. diploidea but has now been identified as $S$. pedata using molecular techniques to identify the amoeba $(191,192)$. It is not known whether the other species ( $S$. diploidea) can cause infections in human or animal hosts.

6.1. Symptoms of SAE. In the single case of Sappinia amoebic encephalitis that has been reported, a sinus infection occurred prior to the onset of symptoms. The individual developed nausea, vomiting, bifrontal headache, photophobia, and blurry vision. A loss of consciousness occurred for a brief period $[7,9,10,191]$. A successful outcome in this patient was reported after surgical excision of a tumorlike mass in the brain and treatment using azithromycin, intravenous pentamidine, itraconazole, and flucytosine [10].

6.2. Diagnosis. A solitary tumor-like mass without an abscess wall in the brain can be observed by MRI for Sappinia encephalitis. The excised mass or biopsy tissue can be fixed and embedded in paraffin. Brain sections stained with $\mathrm{H} \&$ E may exhibit necrotizing hemorrhagic inflammation containing amoebae. Eosinophils and granuloma formation are lacking. Sappinia amoebae can be distinguished from other FLA by the presence of a distinctive double nucleus in which the 2 nuclei are closely apposed with a central flattening $[188,189]$. Two nucleoli are found in the double nucleus. These structures can be observed in paraffin sections stained with $\mathrm{H} \& \mathrm{E}$, Giemsa, or Periodic Acid Schiff. The amoebae are readily observed in cryostat sections stained with $\mathrm{H}$ \& $\mathrm{E}$ 
$[7,10,191]$. Brain tissue can be fixed in glutaraldehyde and prepared for transmission electron microscopy to visualize the amoebae in tissue.

6.3. PCR. Sappinia pedata and S. diploidea can be identified and distinguished by amplification of the SSU rDNA using universal eukaryotic SSU primers followed by an Internal Transcribed Spacer PCR assay. Primers used in the ITS PCR assay are ITS1-P1F5'-GTA ACA AGG TATCCG TAG GTG AAC C-3' and ITS2-P4R: 5'TCC TCC GCT TAT TGA TAT GC-3' [190]. The amoebae originally identified as $S$. diploidea in the single reported case of Sappinia amoebic encephalitis was later identified as S. pedata using newly developed real-time PCR assays based on 18S rRNA gene sequences [191]. The assay specific for Sappinia can be incorporated into the multiplex PCR assay described by Qvarnstrom et al., [57] that distinguish Acanthamoeba, B. mandrillaris, and $N$. fowleri for simultaneous detection of the four genera of FLA that cause infections in humans [191].

6.4. Culture. Sappinia can be cultured on nonnutrient agar coated with bacteria and on tissue culture cells [7].

\section{Conclusion: The Importance of Early Diagnosis}

Although infections with FLA are considered rare, there has been an increase in the number of reported cases in recent years. CNS infections caused by pathogenic freeliving amoebae (FLA) are for the most part fatal. Corneal infection caused by Acanthamoeba can lead to blindness or vision impairment in AK. Recently, it has been shown that there is a greater chance of cure if these infections are detected early and treated timely. However, a fast and efficient diagnosis depends on two variables: the familiarity of practitioner with the symptomatology and treatment of FLA infections, and also the appropriate material to process for a fast and definitive diagnosis. At the present time, it is not known whether FLA infections are rare because they are underreported or due to misdiagnosis. Most infections have been diagnosed postmortem. It is not possible to determine the rarity of these infections, since these infections are relatively unknown, and in many cases autopsies are not performed.

The number of contact lenses users around the world has increased, and consequently AK outbreaks have been more frequent, which requires a faster public health response. GAE and cutaneous acanthamoebiasis can be one of the most frequent secondary diseases in AIDS-HIV patients and in other immunosupressed individuals, since Acanthamoeba is found throughout the world. The dramatic increase in BAE could reflect the potential of this infection to be a common worldwide disease. The increased incidence of PAM caused by $N$. fowleri in recent years may be due to greater recreational activity in warm water lakes and parks. PAM could be avoided with greater awareness of the disease, using public education programs, closing of swimming pools that are improperly chlorinated, and wearing nose clips while diving and engaging in water activities when the nose is submerged. The recent finding of $S$. pedata as a pathogen of the CNS in humans suggests that other free-living amoebae, not yet identified, may be causative of amoebic of amoebic encephalitis.

A more rapid clinical response could provide higher survival rates since treatment is available. Thus, fast and efficient diagnostic tests are pivotal for treatment success. The availability of PCR probes is a promising procedure to obtain fast and specific, confirmatory diagnosis of PAM, GAE, AK, BAE, and SAE in a timely fashion for efficient treatment. To this end, a multiplex PCR assay is available and has been validated as an important and specific tool to identify, N. fowleri, Acanthamoeba spp., and B. mandrillaris in clinical specimens $[57,111]$ but only a few reference laboratories are capable of doing diagnostic detection of FLA [191]. Additionally, a PCR assay has been developed to detect Sappinia in clinical samples [191]. In conclusion, the recognition of these diseases and specific diagnostic tests could lead to earlier treatment and diminish the severity and lethality of these infections in the human host.

\section{Acknowledgment}

This review is dedicated to the memory of Dr. Frederick L. Schuster, a pioneer of the study of free-living amoebae, who published significant contributions in this field in the last 35 years.

\section{References}

[1] M. Fowler and R. Carter, "Acute pyogenic meningitis probably due to Acanthamoeba sp.: a preliminary report," The British Medical Journal, vol. 2, pp. 740-742, 1965.

[2] C. G. Butt, "Primary amebic meningoencephalitis," The New England Journal of Medicine, vol. 274, no. 26, pp. 1473-1476, 1966.

[3] A. J. Martinez, Free-Living Amebas: Natural History, Prevevtion, Diagnosis, Pathology, and Treatment of Disease, CRC Press, Boca Raton, Fla, USA, 1985.

[4] A. J. Martinez, "Free-living amebas: infection of the central nervous system," Mount Sinai Journal of Medicine, vol. 60, no. 4, pp. 271-278, 1993.

[5] A. J. Martinez and G. S. Visvesvara, "Free-living, amphizoic and opportunistic amebas," Brain Pathology, vol. 7, no. 1, pp. 583-598, 1997.

[6] F. Marciano-Cabral and G. Cabral, "Acanthamoeba spp. as agents of disease in humans," Clinical Microbiology Reviews, vol. 16, no. 2, pp. 273-307, 2003.

[7] G. S. Visvesvara, H. Moura, and F. L. Schuster, "Pathogenic and opportunistic free-living amoebae: Acanthamoeba spp., Balamuthia mandrillaris, Naegleria fowleri, and Sappinia diploidea," FEMS Immunology and Medical Microbiology, vol. 50, no. 1, pp. 1-26, 2007.

[8] F. L. Schuster and G. S. Visvesvara, "Free-living amoebae as opportunistic and non-opportunistic pathogens of humans and animals," International Journal for Parasitology, vol. 34, no. 9, pp. 1001-1027, 2004.

[9] B. B. Gelman, S. J. Rauf, R. Nader, et al., "Amoebic encephalitis due to Sappinia diploidea," Journal of the American Medical Association, vol. 285, no. 19, pp. 2450-2451, 2001. 
[10] B. B. Gelman, V. Popov, G. Chaljub, et al., "Neuropathological and ultrastructural features of amebic encephalitis caused by Sappinia diploidea," Journal of Neuropathology and Experimental Neurology, vol. 62, no. 10, pp. 990-998, 2003.

[11] K. Anderson and A. Jamieson, "Primary amoebic meningoencephalitis," The Lancet, vol. 1, no. 7756, pp. 902-903, 1972.

[12] F. Marciano-Cabral, R. MacLean, A. Mensah, and L. LaPatPolasko, "Identification of Naegleria fowleri in domestic water sources by nested PCR," Applied and Environmental Microbiology, vol. 69, no. 10, pp. 5864-5869, 2003.

[13] B. Blair, P. Sarkar, K. R. Bright, F. Marciano-Cabral, and C. P. Gerba, "Naegleria fowleri in well water," Emerging Infectious Diseases, vol. 14, no. 9, pp. 1499-1501, 2008.

[14] M. E. Shoff, A. Rogerson, K. Kessler, S. Schatz, and D. V. Seal, "Prevalence of Acanthamoeba and other naked amoebae in South Florida domestic water," Journal of Water and Health, vol. 6, no. 1, pp. 99-104, 2008.

[15] T. J. Rowbotham, "Current views on the relationships between amoebae, Legionellae and man," Israel Journal of Medical Sciences, vol. 22, no. 9, pp. 678-689, 1986.

[16] J. M. Barbaree, B. S. Fields, J. C. Feeley, G. W. Gorman, and W. T. Martin, "Isolation of protozoa from water associated with legionellosis outbreak and demonstration of intracellular multiplication of Legionella pneumophila," Applied and Environmental Microbiology, vol. 51, no. 2, pp. 422-424, 1986.

[17] T. R. Fritsche, R. K. Gautom, S. Seyedirashti, D. L. Bergeron, and T. D. Lindquist, "Occurrence of bacterial endosymbionts in Acanthamoeba spp. isolated from corneal and environmental specimens and contact lenses," Journal of Clinical Microbiology, vol. 31, no. 5, pp. 1122-1126, 1993.

[18] R. Michel, H. Burghardt, and H. Bergmann, "Acanthamoeba, naturally intracellularly infected with Pseudomonas aeruginosa, after their isolation from a microbiologically contaminated drinking water system in a hospital," Zentralblatt für Hygiene und Umweltmedizin, vol. 196, no. 6, pp. 532-544, 1995.

[19] T. J. Marrie, D. Raoult, B. La Scola, R. J. Birtles, and E. de Carolis, "Legionella-like and other amoebal pathogens as agents of community-acquired pneumonia," Emerging Infectious Diseases, vol. 7, no. 6, pp. 1026-1029, 2001.

[20] F. Marciano-Cabral, K. Han, E. Powell, T. Ferguson, and G. Cabral, "Interaction of an Acanthamoeba human isolate harboring bacteria with murine peritoneal macrophages," Journal of Eukaryotic Microbiology, vol. 50, pp. 516-519, 2003.

[21] J. Barker and M. R. W. Brown, "Trojan Horses of the microbial world: protozoa and the survival of bacterial pathogens in the environment," Microbiology, vol. 140, no. 6, pp. 1253-1259, 1994.

[22] F. Marciano-Cabral, "Introductory remarks: bacterial endosymbionts or pathogens of free-living amebae," Journal of Eukaryotic Microbiology, vol. 51, no. 5, pp. 497-501, 2004.

[23] C. H. King, E. B. Shotts Jr., R. E. Wooley, and K. G. Porter, "Survival of coliforms and bacterial pathogens within protozoa during chlorination," Applied and Environmental Microbiology, vol. 54, no. 12, pp. 3023-3033, 1988.

[24] J. D. Cirillo, S. Falkow, L. S. Tompkins, and L. E. Bermudez, "Interaction of Mycobacterium avium with environmental amoebae enhances virulence," Infection and Immunity, vol. 65, no. 9, pp. 3759-3767, 1997.

[25] E. C. Miltner and L. E. Bermudez, "Mycobacterium avium grown in Acanthamoeba castellanii is protected from the effects of antimicrobials," Antimicrobial Agents and Chemotherapy, vol. 44, no. 7, pp. 1990-1994, 2000.

[26] M. Molmeret, M. Horn, M. Wagner, M. Santic, and Y. Abu Kwaik, "Amoebae as training grounds for intracellular bacterial pathogens," Applied and Environmental Microbiology, vol. 71, no. 1, pp. 20-28, 2005.

[27] F. Marciano-Cabral and G. Cabral, "Naegleria fowleri," in Emerging Protozoan Pathogens, pp. 119-141, Taylor and Francis, New York, NY, USA, 2008.

[28] L. Cerva and K. Novak, "Amoebic meningoencephalitis: sixteen fatalities," Science, vol. 160, no. 3823, p. 92, 1968.

[29] P. Ma, G. S. Visvesvara, A. J. Martinez, F. H. Theodore, P.M. Daggett, and T. K. Sawyer, "Naegleria and Acanthamoeba infections: review," Reviews of Infectious Diseases, vol. 12, no. 3, pp. 490-513, 1990.

[30] J. S. Seidel, P. Harmatz, G. S. Visvesvara, A. Cohen, J. Edwards, and J. Turner, "Successful treatment of primary amebic meningoencephalitis," The New England Journal of Medicine, vol. 306, no. 6, pp. 346-348, 1982.

[31] A. Wang, R. Kay, W. S. Poon, and H. K. Ng, "Successful treatment of amoebic meningoencephalitis in a Chinese living in Hong Kong," Clinical Neurology and Neurosurgery, vol. 95, no. 3, pp. 249-252, 1993.

[32] R. L. Brown, "Successful treatment of primary amebic meningoencephalitis," Archives of Internal Medicine, vol. 151, no. 6, pp. 1201-1202, 1991.

[33] S. C. Parija and S. R. Jayakeerthee, "Naegleria fowleri: a free living amoeba of emerging medical importance," Journal of Communicable Diseases, vol. 31, no. 3, pp. 153-159, 1999.

[34] S. N. Singh, A. K. Patwari, R. Dutta, N. Taneja, and V. K. Anand, "Naegleria meningitis," Indian Journal of Pediatrics, vol. 35, no. 10, pp. 1012-1015, 1998.

[35] J. Vargas-Zepeda, A. V. Gomez-Alcala, J. A. Vasquez-Morales, L. Licea-Amaya, J. F. de Jonckheere, and F. Lares-Villa, "Successful treatment of Naegleria fowleri meningoencephalitis by using intravenous amphotericin B, fluconazole and rifampicin," Archives of Medical Research, vol. 36, no. 1, pp. 83-86, 2005.

[36] S. Shenoy, G. Wilson, H. V. Prashanth, K. Vidyalakshmi, B. Dhanashree, and R. Bharath, "Primary meningoencephalitis by Naegleria fowleri: first reported case from Mangalore, South India," Journal of Clinical Microbiology, vol. 40, no. 1, pp. 309-310, 2002.

[37] R. T. Cursons, J. W. Sleigh, D. Hood, and D. Pullon, "A case of primary amoebic meningoencephalitis: North Island, New Zealand," New Zealand Medical Journal, vol. 116, no. 1187, p. U712, 2003.

[38] N. K. Shrestha, B. Khanal, S. K. Sharma, S. S. Dhakal, and R. Kanungo, "Primary amoebic meningoencephalitis in a patient with systemic lupus erythematosus," Scandinavian Journal of Infectious Diseases, vol. 35, no. 8, pp. 514-516, 2003.

[39] M. Poungvarin and P. Jariya, "The fifth nonlethal case of primary amoebic meningoencephalitis," Journal of the Medical Association of Thailand, vol. 74, no. 2, pp. 112-115, 1991.

[40] "Primary amebic meningoencephalitis—Arizona, Florida, and Texas, 2007," Morbidity and Mortality Weekly Report, vol. 57, no. 21, pp. 573-577, 2008.

[41] D. J. Schumacher, R. D. Tien, and K. Lane, "Neuroimaging findings in rare amebic infections of the central nervous system," American Journal of Neuroradiology, vol. 16, pp. 930935, 1995. 
[42] D. D. Kidney and S. H. Kim, "CNS infections with freeliving amebas: neuroimaging findings," American Journal of Roentgenology, vol. 171, no. 3, pp. 809-812, 1998.

[43] P. Singh, R. Kochhar, R. K. Vashishta, et al., "Amebic meningoencephalitis: spectrum of imaging findings," American Journal of Neuroradiology, vol. 27, no. 6, pp. 1217-1221, 2006.

[44] A. J. Martinez, J. G. dos Santos, E. C. Nelson, W. P. Stamm, and E. Willaert, "Primary amebic meningoencephalitis," in Pathology Annual, S. C. Sommers and P. P. Rosen, Eds., vol. 12, p. 225, Appleton-Century-Crofts, New York, NY, USA, 1977.

[45] A. J. Martinez and G. S. Visvesvara, "Laboratory diagnosis of pathogenic free-living amoebas: Naegleria, Acanthamoeba, and Leptomyxid," Clinics in Laboratory Medicine, vol. 11, no. 4, pp. 861-872, 1991.

[46] O. Sparagano, E. Drouet, R. Brebant, E. Manet, G.-A. Denoyel, and P. Pernin, "Use of monoclonal antibodies to distinguish pathogenic Naegleria fowleri (cysts, trophozoites, or flagellate forms) from other Naegleria species," Journal of Clinical Microbiology, vol. 31, no. 10, pp. 2758-2763, 1993.

[47] F. L. Reveiller, M.-P. Varenne, C. Pougnard, et al., "An enzyme-linked immunosorbent assay (ELISA) for the identification of Naegleria fowleri in environmental water samples," Journal of Eukaryotic Microbiology, vol. 50, no. 2, pp. 109113, 2003.

[48] F. L. Schuster, "Cultivation of pathogenic and opportunistic free-living amebas," Clinical Microbiology Reviews, vol. 15, no. 3, pp. 342-354, 2002.

[49] F. Marciano-Cabral, M. L. Cline, and S. G. Bradley, "Specificity of antibodies from human sera for Naegleria species," Journal of Clinical Microbiology, vol. 25, no. 4, pp. 692-697, 1987.

[50] F. Marciano-Cabral and G. A. Cabral, "The immune response to Naegleria fowleri amebae and pathogenesis of infection," FEMS Immunology and Medical Microbiology, vol. 51, no. 2, pp. 243-259, 2007.

[51] M. Pelandakis, S. Serre, and P. Pernin, "Analysis of the 5.8S rRNA gene and the internal transcribed spacers in Naegleria spp. and in N. fowleri," Journal of Eukaryotic Microbiology, vol. 47, no. 2, pp. 116-121, 2000.

[52] M. Pelandakis and P. Pernin, "Use of multiplex PCR and PCR restriction enzyme analysis for detection and exploration of the variability in the free-living amoeba Naegleria in the environment," Applied and Environmental Microbiology, vol. 68, no. 4, pp. 2061-2065, 2002.

[53] F. L. Reveiller, P.-A. Cabanes, and F. Marciano-Cabral, "Development of a nested PCR assay to detect the pathogenic free-living amoeba Naegleria fowleri," Parasitology Research, vol. 88, no. 5, pp. 443-450, 2002.

[54] B. S. Robinson, P. T. Monis, and P. J. Dobson, "Rapid, sensitive, and discriminating identification of Naegleria spp. by real-time PCR and melting-curve analysis," Applied and Environmental Microbiology, vol. 72, no. 9, pp. 5857-5863, 2006.

[55] J. Behets, P. Declerck, Y. Delaedt, L. Verelst, and F. Ollevier, "A duplex real-time PCR assay for the quantitative detection of Naegleria fowleri in water samples," Water Research, vol. 41, no. 1, pp. 118-126, 2007.

[56] M. Schild, C. Gianinazzi, B. Gottstein, and N. Muller, "PCRbased diagnosis of Naegleria sp. infection in formalin-fixed and paraffin-embedded brain sections," Journal of Clinical Microbiology, vol. 45, no. 2, pp. 564-567, 2007.

[57] Y. Qvarnstrom, G. S. Visvesvara, R. Sriram, and A. J. da Silva, "Multiplex real-time PCR assay for simultaneous detection of
Acanthamoeba spp., Balamuthia mandrillaris, and Naegleria fowleri," Journal of Clinical Microbiology, vol. 44, no. 10, pp. 3589-3595, 2006.

[58] N. A. Khan, "Acanthamoeba: biology and increasing importance in human health," FEMS Microbiology Reviews, vol. 30, no. 4, pp. 564-595, 2006.

[59] F. Marciano-Cabral, R. Puffenbarger, and G. A. Cabral, "The increasing importance of Acanthamoeba infections," Journal of Eukaryotic Microbiology, vol. 47, no. 1, pp. 29-36, 2000.

[60] S. J. Hunt, S. L. Reed, W. C. Mathews, and B. Torian, "Cutaneous Acanthamoeba infection in the acquired immunodeficiency syndrome: response to multidrug therapy," Cutis, vol. 56, no. 5, pp. 285-287, 1995.

[61] G. J. Murakawa, T. McCalmont, J. Altman, et al., "Disseminated acanthamebiasis in patients with AIDS: a report of five cases and a review of the literature," Archives of Dermatology, vol. 131, no. 11, pp. 1291-1296, 1995.

[62] S. Levine, A. E. Goldstein, M. Dahdouh, P. Blank, C. Hoffman, and C. A. Gropper, "Cutaneous Acanthamoeba in a patient with AIDS: a case study with a review of new therapy; quiz 386," Cutis, vol. 67, no. 5, pp. 377-380, 2001.

[63] L. P. May, G. S. Sidhu, and M. R. Buchness, "Diagnosis of Acanthamoeba infection by cutaneous manifestations in a man seropositive to HIV," Journal of the American Academy of Dermatology, vol. 26, no. 2, pp. 352-355, 1992.

[64] J. Helton, M. Loveless, and C. R. White Jr., "Cutaneous Acanthamoeba infection associated with leukocytoclastic vasculitis in an AIDS patient," American Journal of Dermatopathology, vol. 15, no. 2, pp. 146-149, 1993.

[65] P. H. Chandrasekar, P. S. Nandi, M. R. Fairfax, and L. R. Crane, "Cutaneous infections due to Acanthamoeba in patients with acquired immunodeficiency syndrome," Archives of Internal Medicine, vol. 157, no. 5, pp. 569-572, 1997.

[66] M. S. Torno Jr., R. Babapour, A. Gurevitch, and M. D. Witt, "Cutaneous acanthamoebiasis in AIDS," Journal of the American Academy of Dermatology, vol. 42, no. 2, pp. 351354, 2000.

[67] A. G. Duarte, F. Sattar, B. Granwehr, J. F. Aronson, Z. Wang, and S. Lick, "Disseminated acanthamoebiasis after lung transplantation," Journal of Heart and Lung Transplantation, vol. 25, no. 2, pp. 237-240, 2006.

[68] A. J. Martinez, C. A. García, M. Halks-Miller, and R. ArceVela, "Granulomatous amebic encephalitis presenting as a cerebral mass lesion," Acta Neuropathologica, vol. 51, no. 2, pp. 85-91, 1980.

[69] D. O. Matson, E. Rouah, R. T. Lee, D. Armstrong, J. T. Parke, and C. J. Baker, "Acanthameba meningoencephalitis masquerading as neurocysticercosis," Pediatric Infectious Disease Journal, vol. 7, no. 2, pp. 121-124, 1988.

[70] J. P. Sison, C. A. Kemper, M. Loveless, D. McShane, G. S. Visvesvara, and S. C. Deresinski, "Disseminated Acanthamoeba infection in patients with AIDS: case reports and review," Clinical Infectious Diseases, vol. 20, no. 5, pp. 12071216, 1995.

[71] S. K. Ofori-Kwakye, D. G. Sidebottom, J. Herbert, E. G. Fischer, and G. S. Visvesvara, "Granulomatous brain tumor caused by Acanthamoeba," Journal of Neurosurgery, vol. 64, no. 3, pp. 505-509, 1986.

[72] J. J. Sell, F. W. Rupp, and W. W. Orrison Jr., "Granulomatous amebic encephalitis caused by Acanthamoeba," Neuroradiology, vol. 39, no. 6, pp. 434-436, 1997. 
[73] H. A. R. Gardner, A. J. Martinez, G. S. Visvesvara, and A. Sotrel, "Granulomatous amebic encephalitis in an AIDS patient," Neurology, vol. 41, no. 12, pp. 1993-1995, 1991.

[74] C. G. Culbertson and K. Harper, "Pathogenic free-living amebae. Immunocytologic demonstration and species identification," American Journal of Tropical Medicine and Hygiene, vol. 33, no. 5, pp. 851-856, 1984.

[75] B. Tan, C. M. Weldon-Linne, D. P. Rhone, C. L. Penning, and G. S. Visvesvara, "Acanthamoeba infection presenting as skin lesions in patients with the acquired immunodeficiency syndrome," Archives of Pathology and Laboratory Medicine, vol. 117, no. 10, pp. 1043-1046, 1993.

[76] M. S. Martinez, G. Gonzalez-Mediero, P. Santiago, et al., "Granulomatous amebic encephalitis in a patient with AIDS: isolation of Acanthamoeba sp. group II from brain tissue and successful treatment with sulfadiazine and fluconazole," Journal of Clinical Microbiology, vol. 38, no. 10, pp. 3892 3895, 2000.

[77] R. Cursons, "A simple staining method for the detection of amoebae," New Zealand Medical Journal, vol. 94, no. 698, p. 471, 1981.

[78] T.-W. Hahn, T. P. O’Brien, W.-J. Sah, and J.-H. Kim, “Acridine orange staining for rapid diagnosis of Acanthamoeba keratitis," Japanese Journal of Ophthalmology, vol. 42, no. 2, pp. 108-114, 1998.

[79] C. W. B. Walker, "Acanthamoeba: ecology, pathogenicity and laboratory detection," British Journal of Biomedical Science, vol. 53, no. 2, pp. 146-151, 1996.

[80] F. Petry, M. Torzewski, J. Bohl, et al., "Early diagnosis of Acanthamoeba infection during routine cytological examination of cerebrospinal fluid," Journal of Clinical Microbiology, vol. 44, no. 5, pp. 1903-1904, 2006.

[81] J. P. Steinberg, R. L. Galindo, E. S. Kraus, and K. G. Ghanem, "Disseminated acanthamebiasis in a renal transplant recipient with osteomyelitis and cutaneous lesions: case report and literature review," Clinical Infectious Diseases, vol. 35, no. 5, pp. e43-e49, 2002.

[82] E. Willaert, A. R. Stevens, and G. R. Healy, "Retrospective identification of Acanthamoeba culbertsoni in a case of amoebic meningoencephalitis," Journal of Clinical Pathology, vol. 31, no. 8, pp. 717-720, 1978.

[83] M. S. McKellar, L. R. Mehta, J. E. Greenlee, et al., "Fatal granulomatous Acanthamoeba encephalitis mimicking a stroke, diagnosed by correlation of results of sequential magnetic resonance imaging, biopsy, in vitro culture, immunofluorescence analysis, and molecular analysis," Journal of Clinical Microbiology, vol. 44, no. 11, pp. 4265-4269, 2006.

[84] J. Guarner, J. Bartlett, W.-J. Shieh, C. D. Paddock, G. S. Visvesvara, and S. R. Zaki, "Histopathologic spectrum and immunohistochemical diagnosis of amebic meningoencephalitis," Modern Pathology, vol. 20, no. 12, pp. 1230-1237, 2007.

[85] J. M. Feingold, J. Abraham, S. Bilgrami, et al., “Acanthamoeba meningoencephalitis following autologous peripheral stem cell transplantation," Bone Marrow Transplantation, vol. 22, no. 3, pp. 297-300, 1998.

[86] K. C. Bloch and F. L. Schuster, "Inability to make a premortem diagnosis of Acanthamoeba species infection in a patient with fatal granulomatous amebic encephalitis," Journal of Clinical Microbiology, vol. 43, no. 6, pp. 3003-3006, 2005.

[87] C. G. Shirwadkar, R. Samant, M. Sankhe, et al., "Acanthamoeba encephalitis in patient with systemic lupus, India," Emerging Infectious Diseases, vol. 12, no. 6, pp. 984-986, 2006.
[88] M. L. Turner, E. J. Cockerell, H. M. Brereton, et al., "Antigens of selected Acanthamoeba species detected with monoclonal antibodies," International Journal for Parasitology, vol. 35, no. 9, pp. 981-990, 2005.

[89] C. A. Wiley, R. E. Safrin, C. E. Davis, et al., "Acanthamoeba meningoencephalitis in a patient with AIDS," Journal of Infectious Diseases, vol. 155, no. 1, pp. 130-133, 1987.

[90] S. E. Vernon, B. C. Acar, S. M. Pham, and D. Fertel, "Acanthamoeba infection in lung transplantation: report of a case and review of the literature," Transplant Infectious Disease, vol. 7, no. 3-4, pp. 154-157, 2005.

[91] G. S. Visvesvara, D. B. Jones, and N. M. Robinson, "Isolation, identification, and biological characterization of Acanthamoeba polyphaga from a human eye," American Journal of Tropical Medicine and Hygiene, vol. 24, no. 5, pp. 784-790, 1975.

[92] L. Cerva, "Acanthamoeba culbertsoni and Naegleria fowleri: occurrence of antibodies in man," Journal of Hygiene Epidemiology Microbiology and Immunology, vol. 33, no. 1, pp. 99-103, 1989.

[93] R. T. M. Cursons, T. J. Brown, E. A. Keys, K. M. Moriarty, and D. Till, "Immunity to pathogenic free-living amoebae: role of humoral antibody," Infection and Immunity, vol. 29, no. 2, pp. 401-407, 1980.

[94] C. A. Slater, J. Z. Sickel, G. S. Visvesvara, R. C. Pabico, and A. A. Gaspari, "Brief report: successful treatment of disseminated Acanthamoeba infection in an immunocompromised patient," The New England Journal of Medicine, vol. 331, no. 2, pp. 85-87, 1994.

[95] N. Brindley, A. Matin, and N. A. Khan, "Acanthamoeba castellanii: high antibody prevalence in racially and ethnically diverse populations," Experimental Parasitology, vol. 121, no. 3, pp. 254-256, 2009.

[96] F. L. Schuster, S. Honarmand, G. S. Visvesvara, and C. A. Glaser, "Detection of antibodies against free-living amoebae Balamuthia mandrillaris and Acanthamoeba species in a population of patients with encephalitis," Clinical Infectious Diseases, vol. 42, no. 9, pp. 1260-1265, 2006.

[97] E. L. Powell, A. L. Newsome, S. D. Allen, and G. B. Knudson, "Identification of antigens of pathogenic free-living amoebae by protein immunoblotting with rabbit immune and human sera," Clinical and Diagnostic Laboratory Immunology, vol. 1, no. 5, pp. 493-499, 1994.

[98] C. L. Chappell, J. A. Wright, M. Coletta, and A. L. Newsome, "Standardized method of measuring Acanthamoeba antibodies in sera from healthy human subjects," Clinical and Diagnostic Laboratory Immunology, vol. 8, no. 4, pp. 724-730, 2001.

[99] M. H. Vodkin, D. K. Howe, G. S. Visvesvara, and G. L. McLaughlin, "Identification of Acanthamoeba at the generic and specific levels using the polymerase chain reaction," Journal of Protozoology, vol. 39, no. 3, pp. 378-385, 1992.

[100] J. M. Schroeder, G. C. Booton, J. Hay, et al., "Use of subgenic $18 \mathrm{~S}$ ribosomal DNA PCR and sequencing for genus and genotype identification of Acanthamoebae from humans with keratitis and from sewage sludge," Journal of Clinical Microbiology, vol. 39, no. 5, pp. 1903-1911, 2001.

[101] N. A. Khan, E. L. Jarroll, and T. A. Paget, "Acanthamoeba can be differentiated by the polymerase chain reaction and simple plating assays," Current Microbiology, vol. 43, no. 3, pp. 204208, 2001.

[102] J. Lorenzo-Morales, J. F. Lindo, E. Martinez, et al., "Pathogenic Acanthamoeba strains from water sources in 
Jamaica, West Indies," Annals of Tropical Medicine and Parasitology, vol. 99, no. 8, pp. 751-758, 2005.

[103] R. C. MacLean, N. Hafez, S. Tripathi, C. G. Childress, N. R. Ghatak, and F. Marciano-Cabral, "Identification of Acanthamoeba sp. in paraffin-embedded CNS tissue from an HIV+ individual by PCR," Diagnostic Microbiology and Infectious Disease, vol. 57, no. 3, pp. 289-294, 2007.

[104] W. Meersseman, K. Lagrou, R. Sciot, et al., "Rapidly fatal Acanthamoeba encephalitis and treatment of cryoglobulinemia," Emerging Infectious Diseases, vol. 13, no. 3, pp. 469-471, 2007.

[105] J. Walochnik, A. Aichelburg, O. Assadian, et al., "Granulomatous amoebic encephalitis caused by Acanthamoeba amoebae of genotype T2 in a human immunodeficiency virus-negative patient," Journal of Clinical Microbiology, vol. 46, no. 1, pp. 338-340, 2008.

[106] P. Goldschmidt, S. Degorge, C. Saint-Jean, et al., "Resistance of Acanthamoeba to classic DNA extraction methods used for the diagnosis of corneal infections," British Journal of Ophthalmology, vol. 92, no. 1, pp. 112-115, 2008.

[107] G. C. Booton, G. S. Visvesvara, T. J. Byers, D. J. Kelly, and P. A. Fuerst, "Identification and distribution of Acanthamoeba species genotypes associated with nonkeratitis infections," Journal of Clinical Microbiology, vol. 43, no. 4, pp. 1689-1693, 2005.

[108] S. Yagi, F. L. Schuster, and K. Bloch, "Demonstration of presence of Acanthamoeba mitochondrial DNA in brain tissue and cerebrospinal fluid by PCR in samples from a patient who died of granulomatous amebic encephalitis," Journal of Clinical Microbiology, vol. 45, no. 6, pp. 2090-2091, 2007.

[109] S. Yagi, F. L. Schuster, and G. S. Visvesvara, "Demonstration of Balamuthia and Acanthamoeba mitochondrial DNA in sectioned archival brain and other tissues by the polymerase chain reaction," Parasitology Research, vol. 102, no. 3, pp. 491-497, 2008.

[110] D. Rivière, F. M. Szczebara, J.-M. Berjeaud, J. Frère, and Y. Héchard, "Development of a real-time PCR assay for quantification of Acanthamoeba trophozoites and cysts," Journal of Microbiological Methods, vol. 64, no. 1, pp. 78-83, 2006.

[111] P. P. Thompson, R. P. Kowalski, R. M. Q. Shanks, and Y. J. Gordon, "Validation of real-time PCR for laboratory diagnosis of Acanthamoeba keratitis," Journal of Clinical Microbiology, vol. 46, no. 10, pp. 3232-3236, 2008.

[112] C. D. Illingworth and S. D. Cook, "Acanthamoeba keratitis," Survey of Ophthalmology, vol. 42, no. 6, pp. 493-508, 1998.

[113] N. Thebpatiphat, K. M. Hammersmith, F. N. Rocha, et al., "Acanthamoeba keratitis: a parasite on the rise," Cornea, vol. 26, no. 6, pp. 701-706, 2007.

[114] D. W. Clarke and J. Y. Niederkorn, "The pathophysiology of Acanthamoeba keratitis," Trends in Parasitology, vol. 22, no. 4, pp. 175-180, 2006.

[115] S. T. Awwad, W. M. Petroll, J. P. McCulley, and H. D. Cavanagh, "Updates in Acanthamoeba keratitis," Eye and Contact Lens, vol. 33, no. 1, pp. 1-8, 2007.

[116] K. R. Wilhelmus, D. B. Jones, A. Y. Matoba, M. B. Hamill, S. C. Pflugfelder, and M. P. Weikert, "Bilateral Acanthamoeba keratitis," American Journal of Ophthalmology, vol. 145, no. 2, pp. 193-197, 2008.

[117] F. H. Theodore, F. A. Jakobiec, K. B. Juechter, et al., "The diagnostic value of a ring infiltrate in acanthamoebic keratitis," Ophthalmology, vol. 92, no. 11, pp. 1471-1479, 1985.
[118] M. B. Moore, J. P. McCulley, H. E. Kaufman, and J. B. Robin, "Radial keratoneuritis as a presenting sign in Acanthamoeba keratitis," Ophthalmology, vol. 93, no. 10, pp. 1310-1315, 1986.

[119] A. S. Bacon, J. K. G. Dart, L. A. Ficker, M. M. Matheson, and P. Wright, "Acanthamoeba keratitis: the value of early diagnosis," Ophthalmology, vol. 100, no. 8, pp. 1238-1243, 1993.

[120] I. Kremer, E. J. Cohen, R. C. Eagle Jr., I. Udell, and P. R. Laibson, "Histopathologic evaluation of stromal inflammation in Acanthamoeba keratitis," CLAO Journal, vol. 20, no. 1, pp. 4548, 1994.

[121] S. Sharma, P. Garg, and G. N. Rao, "Patient characteristics, diagnosis, and treatment of non-contact lens related Acanthamoeba keratitis," British Journal of Ophthalmology, vol. 84, no. 10, pp. 1103-1108, 2000.

[122] D. V. Seal, "Acanthamoeba keratitis update-incidence, molecular epidemiology and new drugs for treatment," Eye, vol. 17, no. 8, pp. 893-905, 2003.

[123] C. E. Joslin, E. Y. Tu, M. E. Shoff, et al., "The association of contact lens solution use and Acanthamoeba keratitis," American Journal of Ophthalmology, vol. 144, no. 2, pp. 169180.e2, 2007.

[124] K. J. Johns, D. M. O’Day, and W. S. Head, "Herpes simplex masquerade syndrome: Acanthamoeba keratitis," Current Eye Research, vol. 6, no. 1, pp. 207-212, 1987.

[125] J. P. McCulley, H. Alizadeh, and J. Y. Niederkorn, "The diagnosis and management of Acanthamoeba keratitis," CLAO Journal, vol. 26, no. 1, pp. 47-51, 2000.

[126] S. L. Karayianis, L. J. Genack, M. K. Lundergan, and G. B. Schumann, "Cytologic diagnosis of acanthamoebic keratitis," Acta Cytologica, vol. 32, no. 4, pp. 491-494, 1988.

[127] O. E. Lund, F. H. Stefani, and W. Dechant, "Amoebic keratitis: a clinicopathological case report," British Journal of Ophthalmology, vol. 62, no. 6, pp. 373-375, 1978.

[128] M. M. Qureshi and E. J. Bottone, "Acanthamoeba keratitis: a rational approach to microbiological diagnosis," Medical Microbiology Letters, vol. 2, pp. 117-124, 1993.

[129] H. E. Grossniklaus, G. O. Waring IV, C. Akor, A. A. Castellano-Sanchez, and K. Bennett, "Evaluation of hematoxylin and eosin and special stains for the detection of Acanthamoeba keratitis in penetrating keratoplasties," American Journal of Ophthalmology, vol. 136, no. 3, pp. 520-526, 2003.

[130] M. J. Bharathi, R. Ramakrishnan, R. Meenakshi, S. Mittal, C. Shivakumar, and M. Srinivasan, "Microbiological diagnosis of infective keratitis: comparative evaluation of direct microscopy and culture results," British Journal of Ophthalmology, vol. 90, no. 10, pp. 1271-1276, 2006.

[131] N. Gupta and R. Tandon, "Investigative modalities in infectious keratitis," Indian Journal of Ophthalmology, vol. 56, no. 3, pp. 209-213, 2008.

[132] J. de Nadai Barros, V. L. Degaspare-Mascaro, M. Lowen, M. C. Martins, and A. Foronda, "Diagnosis of Acanthamoeba corneal Infection by impression cytology: case report," Arquivos Brasileiros de Oftalmologia, vol. 70, no. 2, pp. 343346, 2007.

[133] W. Mathers, G. Stevens Jr., and M. Rodrigues, "Immunopathology and electron microscopy of Acanthamoeba keratitis," American Journal of Ophthalmology, vol. 103, no. 5, part 3, pp. 626-635, 1987.

[134] K. M. Hammersmith, "Diagnosis and management of Acanthamoeba keratitis," Current Opinion in Ophthalmology, vol. 17 , no. 4, pp. 327-331, 2006. 
[135] H. Kaur, L. J. Maguire, D. R. Salomao, and J. D. Cameron, "Rapid progression of amebic keratitis 1 week after corneal trauma and 1 year after LASIK," Cornea, vol. 26, no. 2, pp. 212-214, 2007.

[136] R. J. Epstein, L. A. Wilson, G. S. Visvesvara, and E. G. Plourde Jr., "Rapid diagnosis of Acanthamoeba keratitis from corneal scrapings using indirect fluorescent antibody staining," Archives of Ophthalmology, vol. 104, no. 9, pp. 1318-1321, 1986.

[137] F. Rivasi, L. Longanesi, C. Casolari, et al., "Cytologic diagnosis of Acanthamoeba keratitis: report of a case with correlative study with indirect immunofluorescence and scanning electron microscopy," Acta Cytologica, vol. 39, no. 4, pp. 821-826, 1995.

[138] K. R. Wilhelmus, M. S. Osato, and R. L. Font, "Rapid diagnosis of Acanthamoeba keratitis using calcofluor white," Archives of Ophthalmology, vol. 104, no. 9, pp. 1309-1312, 1986.

[139] R. E. Silvany, M. W. Luckenbach, and M. B. Moore, "The rapid detection of Acanthamoeba in parafin-embedded secton of corneal tissue with calcofluor white," Archives of Ophthalmology, vol. 105, no. 10, pp. 1366-1367, 1987.

[140] D. N. Parmar, S. T. Awwad, W. M. Petroll, R. W. Bowman, J. P. McCulley, and H. D. Cavanagh, "Tandem scanning confocal corneal microscopy in the diagnosis of suspected Acanthamoeba keratitis," Ophthalmology, vol. 113, no. 4, pp. 538-547, 2006.

[141] H. D. Cavanagh, W. M. Petroll, H. Alizadeh, Y.-G. He, J. P. McCulley, and J. V. Jester, "Clinical and diagnostic use of in vivo confocal microscopy in patients with corneal disease," Ophthalmology, vol. 100, no. 10, pp. 1444-1454, 1993.

[142] K. Winchester, W. D. Mathers, J. E. Sutphin, and T. E. Daley, "Diagnosis of Acanthamoeba keratitis in vivo with confocal microscopy," Cornea, vol. 14, no. 1, pp. 10-17, 1995.

[143] D. R. Pfister, J. D. Cameron, J. H. Krachmer, and E. J. Holland, "Confocal microscopy findings of Acanthamoeba keratitis," American Journal of Ophthalmology, vol. 121, no. 2, pp. 119128, 1996.

[144] B. J. Cho and E. J. Holland, "In vivo tandem scanning confocal microscopy in Acanthamoeba keratitis," Korean Journal of Ophthalmology, vol. 12, no. 2, pp. 112-117, 1998.

[145] S. C. Kaufman, D. C. Musch, M. W. Belin, et al., "Confocal microscopy: a report by the American Academy of Ophthalmology," Ophthalmology, vol. 111, no. 2, pp. 396-406, 2004.

[146] Y. Matsumoto, M. Dogru, E. A. Sato, et al., "The application of in vivo confocal scanning laser microscopy in the management of Acanthamoeba keratitis," Molecular Vision, vol. 13, pp. 1319-1326, 2007.

[147] A. Kobayashi, Y. Ishibashi, Y. Oikawa, H. Yokogawa, and K. Sugiyama, "In vivo and ex vivo laser confocal microscopy findings in patients with early-stage Acanthamoeba keratitis," Cornea, vol. 27, no. 4, pp. 439-445, 2008.

[148] E. Y. Tu, C. E. Joslin, J. Sugar, G. C. Booton, M. E. Shoff, and P. A. Fuerst, "The relative value of confocal microscopy and superficial corneal scrapings in the diagnosis of Acanthamoeba keratitis," Cornea, vol. 27, no. 7, pp. 764772, 2008.

[149] J. A. Irvine and R. Ariyasu, "Limitations in tandem scanning confocal microscopy as a diagnostic tool for microbial keratitis," Scanning, vol. 16, no. 5, pp. 307-311, 1994.

[150] S. Kilvington, D. F. P. Larkin, D. G. White, and J. R. Beeching, "Laboratory investigation of Acanthamoeba keratitis," Journal of Clinical Microbiology, vol. 28, no. 12, pp. 2722-2725, 1990.
[151] S. M. Lee, Y. J. Choi, H. W. Ryu, H. H. Kong, and D. I. Chung, "Species identification and molecular characterization of Acanthamoeba isolated from contact lens paraphernalia," Korean Journal of Ophthalmology, vol. 11, no. 1, pp. 39-50, 1997.

[152] M. Boost, P. Cho, S. Lai, and W. M. Sun, "Detection of Acanthamoeba in tap water and contact lens cases using polymerase chain reaction," Optometry and Vision Science, vol. 85, no. 7, pp. 526-530, 2008.

[153] O. J. Lehmann, S. M. Green, N. Morlet, et al., "Polymerase chain reaction analysis of corneal epithelial and tear samples in the diagnosis of Acanthamoeba keratitis," Investigative Ophthalmology and Visual Science, vol. 39, no. 7, pp. 12611265, 1998.

[154] H. Yera, O. Zamfir, T. Bourcier, et al., "Comparison of PCR, microscopic examination and culture for the early diagnosis and characterization of Acanthamoeba isolates from ocular infections," European Journal of Clinical Microbiology and Infectious Diseases, vol. 26, no. 3, pp. 221-224, 2007.

[155] P. Goldschmidt, H. Rostane, C. Saint-Jean, et al., "Effects of topical anaesthetics and fluorescein on the real-time PCR used for the diagnosis of Herpesviruses and Acanthamoeba keratitis," British Journal of Ophthalmology, vol. 90, no. 11, pp. 1354-1356, 2006.

[156] G. S. Visvesvara, A. J. Martinez, F. L. Schuster, et al., "Leptomyxid ameba, a new agent of amebic meningoencephalitis in humans and animals," Journal of Clinical Microbiology, vol. 28, no. 12, pp. 2750-2756, 1990.

[157] G. S. Visvesvara, F. L. Schuster, and A. J. Martinez, "Balamuthia mandrillaris, N. G., N. Sp., agent of amebic meningoencephalitis in humans and other animals," The Journal of Eukaryotic Microbiology, vol. 40, no. 4, pp. 504514, 1993.

[158] A. J. Martinez and G. S. Visvesvara, "Balamuthia mandrillaris infection," Journal of Medical Microbiology, vol. 50, no. 3, pp. 205-207, 2001.

[159] F. L. Schuster and G. S. Visvesvara, "Balamuthia mandrillaris," in Emerging Protozoan Pathogens, N. A. Khan, Ed., pp. 71-118, Taylor \& Francis, New York, NY, USA, 2008.

[160] F. L. Schuster, T. H. Dunnebacke, G. C. Booton, et al., "Environmental isolation of Balamuthia mandrillaris associated with a case of amebic encephalitis," Journal of Clinical Microbiology, vol. 41, no. 7, pp. 3175-3180, 2003.

[161] T. H. Dunnebacke, F. L. Schuster, S. Yagi, and G. C. Booton, "Balamuthia mandrillaris from soil samples," Microbiology, vol. 150, no. 9, pp. 2837-2842, 2004.

[162] O. Foreman, J. Sykes, L. Ball, N. Yang, and H. De Cock, "Disseminated infection with Balamuthia mandrillaris in a dog," Veterinary Pathology, vol. 41, no. 5, pp. 506-510, 2004.

[163] P. Intalapaporn, C. Suankratay, S. Shuangshoti, K. Phantumchinda, S. Keelawat, and H. Wilde, "Balamuthia mandrillaris meningoencephalitis: the first case in Southeast Asia," American Journal of Tropical Medicine and Hygiene, vol. 70, no. 6, pp. 666-669, 2004.

[164] R. P. Reed, C. M. Cooke-Yarborough, A. L. Jaquiery, et al., "Fatal granulomatous amoebic encephalitis caused by Balamuthia mandrillaris," Medical Journal of Australia, vol. 167, no. 2, pp. 82-84, 1997.

[165] J. M. Riestra-Castaneda, R. Riestra-Castaneda, A. A. Gonzalez-Garrido, et al., "Granulomatous amebic encephalitis due to Balamuthia mandrillaris (Leptomyxiidae): report of four cases from Mexico," American Journal of Tropical Medicine and Hygiene, vol. 56, no. 6, pp. 603-607, 1997. 
[166] T. R. Deetz, M. H. Sawyer, G. Billman, F. L. Schuster, and G. S. Visvesvara, "Successful treatment of Balamuthia amoebic encephalitis: presentation of 2 cases," Clinical Infectious Diseases, vol. 37, no. 10, pp. 1304-1312, 2003.

[167] F. Bravo and M. R. Sanchez, "New and re-emerging cutaneous infectious diseases in Latin America and other geographic areas," Dermatologic Clinics, vol. 21, no. 4, pp. 655-668, 2003.

[168] A. S. Pritzker, B. K. Kim, D. Agrawal, P. M. Southern Jr., and A. G. Pandya, "Fatal granulomatous amebic encephalitis caused by Balamuthia mandrillaris presenting as a skin lesion," Journal of the American Academy of Dermatology, vol. 50, no. 2, pp. S38-S41, 2004.

[169] A. Matin, R. Siddiqui, S. Jayasekera, and N. A. Khan, "Increasing importance of Balamuthia mandrillaris," Clinical Microbiology Reviews, vol. 21, no. 3, pp. 435-448, 2008.

[170] C. F. Denney, V. J. Iragui, L. D. Uber-Zak, et al., "Amebic meningoencephalitis caused by Balamuthia mandrillaris: case report and review," Clinical Infectious Diseases, vol. 25, no. 6, pp. 1354-1358, 1997.

[171] J. F. Healy, "Balamuthia amebic encephalitis: radiographic and pathologic findings," American Journal of Neuroradiology, vol. 23, no. 3, pp. 486-489, 2002.

[172] S. Jung, R. L. Schelper, G. S. Visvesvara, and H. T. Chang, "Balamuthia mandrillaris meningoencephalitis in an immunocompetent patient: an unusual clinical course and a favorable outcome," Archives of Pathology and Laboratory Medicine, vol. 128, no. 4, pp. 466-468, 2004.

[173] A. Bakardjiev, P. H. Azimi, N. Ashouri, et al., "Amebic encephalitis caused by Balamuthia mandrillaris: report of four cases," Pediatric Infectious Disease Journal, vol. 22, no. 5, pp. 447-452, 2003.

[174] D. A. Griesemer, L. L. Barton, C. M. Reese, et al., "Amebic meningoencephalitis caused by Balamuthia mandrillaris," Pediatric Neurology, vol. 10, no. 3, pp. 249-254, 1994.

[175] J. L. Rowen, C. A. Doerr, H. Vogel, and C. J. Baker, “Balamuthia mandrillaris: a newly recognized agent for amebic meningoencephalitis," Pediatric Infectious Disease Journal, vol. 14, no. 8, pp. 705-710, 1995.

[176] I. Bodi, N. Dutt, T. Hampton, and N. Akbar, "Fatal granulomatous amoebic meningoencephalitis due to Balamuthia mandrillaris," Pathology Research and Practice, vol. 204, no. 12, pp. 925-928, 2008.

[177] S. Jayasekera, J. Sissons, J. Tucker, et al., "Post-mortem culture of Balamuthia mandrillaris from the brain and cerebrospinal fluid of a case of granulomatous amoebic meningoencephalitis, using human brain microvascular endothelial cells," Journal of Medical Microbiology, vol. 53, no. 10, pp. 1007-1012, 2004.

[178] R. Kodet, E. Nohýnková, M. Tichý, J. Soukup, and G. S. Visvesvara, "Amebic encephalitis caused by Balamuthia mandrillaris in a Czech child: description of the first case from Europe," Pathology Research and Practice, vol. 194, no. 6, pp. 423-429, 1998.

[179] B. J. Duke, R. W. Tyson, R. DeBiasi, J. E. Freeman, and K. R. Winston, "Balamuthia mandrillaris meningoencephalitis presenting with acute hydrocephalus," Pediatric Neurosurgery, vol. 26, no. 2, pp. 107-111, 1997.

[180] Z. H. Huang, A. Ferrante, and R. F. Carter, "Serum antibodies to Balamuthia mandrillaris, a free-living amoeba recently demonstrated to cause granulomatous amoebic encephalitis," Journal of Infectious Diseases, vol. 179, no. 5, pp. 13051308, 1999.
[181] F. L. Schuster, S. Honarmand, G. S. Visvesvara, and C. A. Glaser, "Detection of antibodies against free-living amoebae Balamuthia mandrillaris and Acanthamoeba species in a population of patients with encephalitis," Clinical Infectious Diseases, vol. 42, no. 9, pp. 1260-1265, 2006.

[182] A. F. Kiderlen, E. Radam, and P. S. Tata, "Assessment of Balamuthia mandrillaris-specific serum antibody concentrations by flow cytometry," Parasitology Research, vol. 104, no. 3, pp. 663-670, 2009.

[183] G. C. Booton, J. R. Carmichael, G. S. Visvesvara, T. J. Byers, and P. A. Fuerst, "Genotyping of Balamuthia mandrillaris based on nuclear $18 \mathrm{~S}$ and mitochondrial 16s rRNA genes," American Journal of Tropical Medicine and Hygiene, vol. 68, no. 1, pp. 65-69, 2003.

[184] G. C. Booton, J. R. Carmichael, G. S. Visvesvara, T. J. Byers, and P. A. Fuerst, "Identification of Balamuthia mandrillaris by PCR assay using the mitochondrial $16 \mathrm{~S}$ rRNA gene as a target," Journal of Clinical Microbiology, vol. 41, no. 1, pp. 453-455, 2003.

[185] S. Yagi, G. C. Booton, G. S. Visvesvara, and F. L. Schuster, "Detection of Balamuthia mitochondrial 16S rRNA gene DNA in clinical specimens by PCR," Journal of Clinical Microbiology, vol. 43, no. 7, pp. 3192-3197, 2005.

[186] M. Tavares, J. M. C. da Costa, S. S. Carpenter, et al., "Diagnosis of first case of Balamuthia amoebic encephalitis in Portugal by immunofluorescence and PCR," Journal of Clinical Microbiology, vol. 44, no. 7, pp. 2660-2663, 2006.

[187] A. F. Kiderlen, E. Radam, and A. Lewin, "Detection of Balamuthia mandrillaris DNA by real-time PCR targeting the RNase P gene," BMC Microbiology, vol. 8, article 210, 2008.

[188] R. Michel, C. Wylezich, B. Hauroder, and A. V. Smirnov, "Phylogenetic position and notes on the ultrastructure of Sappinia diploidea (Thecamoebidae)," Protistology, vol. 4, pp. 319-325, 2006.

[189] L. P. Goodfellow, J. H. Belcher, and F. C. Page, "A light and electron microscopical study of Sappinia diploidea, a sexual amoeba," Protistologica, vol. 2, pp. 207-216, 1974.

[190] M. W. Brown, F. W. Spiegel, and J. D. Silberman, "Amoeba at attention: phylogenetic affinity of Sappinia pedata," Journal of Eukaryotic Microbiology, vol. 54, no. 6, pp. 511-519, 2007.

[191] Y. Qvarnstrom, A. J. da Silva, F. L. Schuster, B. B. Gelman, and G. S. Visvesvara, "Molecular confirmation of Sappinia pedata as a causative agent of amoebic encephalitis," Journal of Infectious Diseases, vol. 199, no. 8, pp. 1139-1142, 2009. 


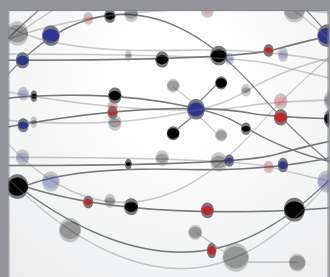

The Scientific World Journal
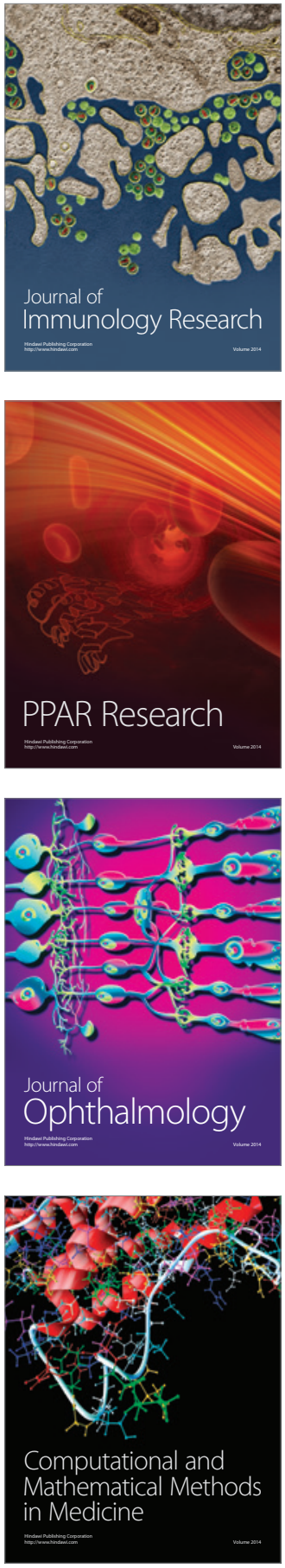

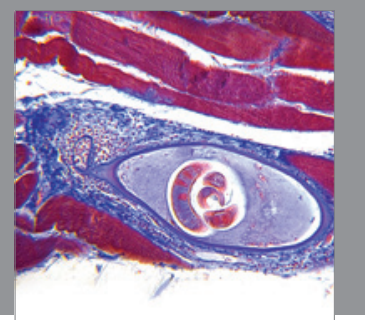

Gastroenterology

Research and Practice
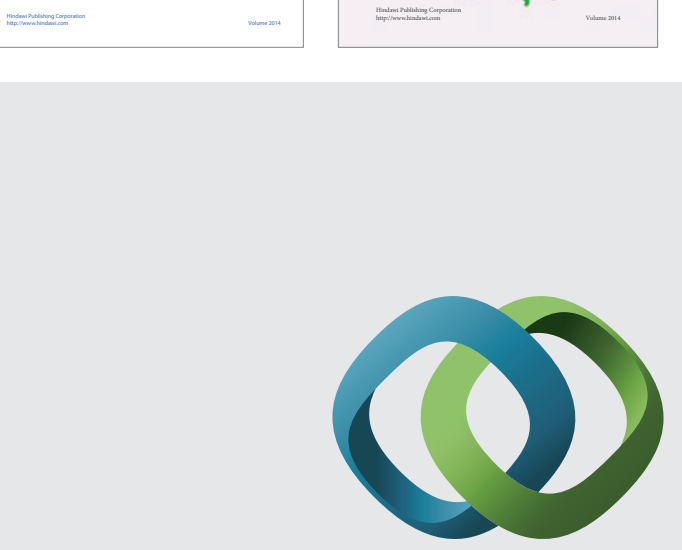

\section{Hindawi}

Submit your manuscripts at

http://www.hindawi.com
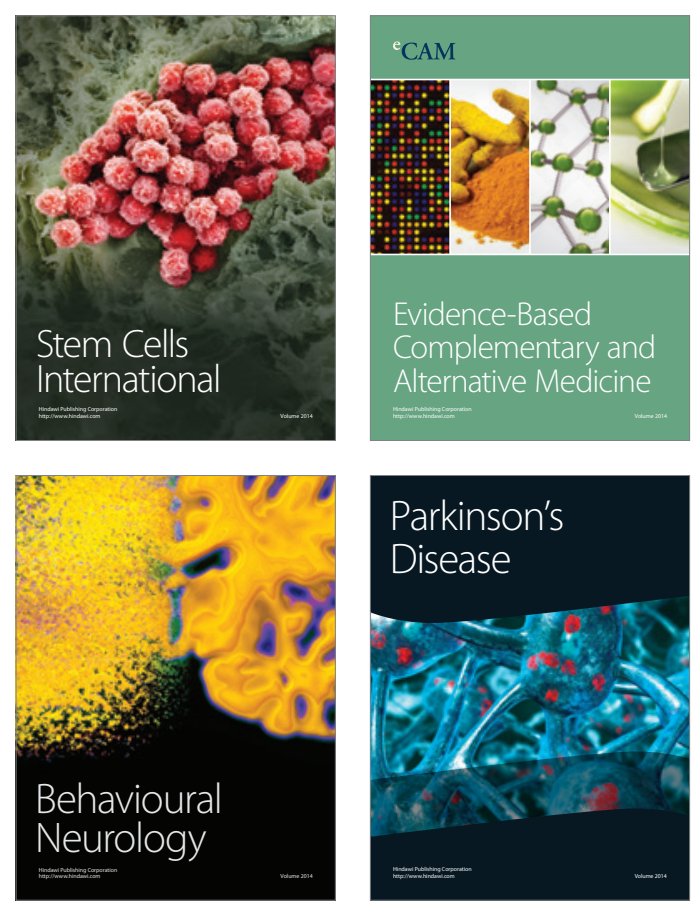

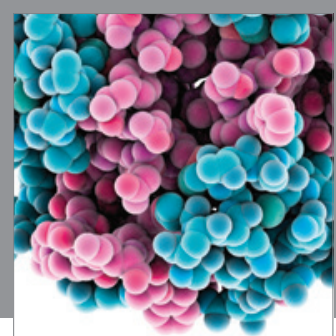

Journal of
Diabetes Research

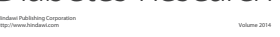

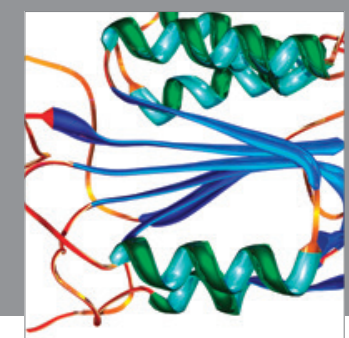

Disease Markers
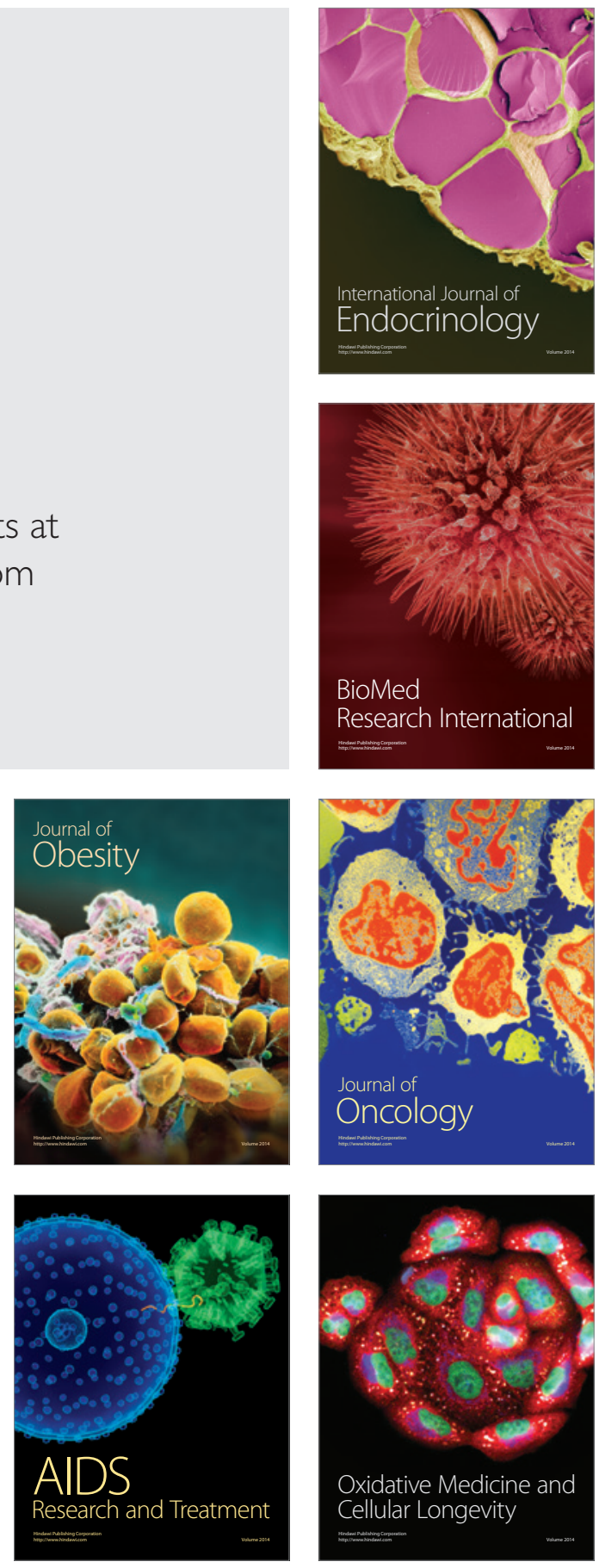